\title{
Domestic violence against married women in reproductive age group: A community based study.
}

\author{
Authors: Aswar N.R ${ }^{1}$, Kale Kalpana $\mathrm{M}^{2}$, Inamdar I.F ${ }^{3}$, Sonali Borkar ${ }^{4}$, \\ Doibale M.K \\ 1-Associate Professor - Department of Community Medicine \\ 2-Associate Professor- Department of Community Medicine, GMC Akola \\ 3-Assistant Professor - Department of Community Medicine \\ 4- Lady medical Officer-Department of Community Medicine, GMC Akola \\ 5-Professor \& Head-Department of Community Medicine \\ Dr. S.C. Government Medical College, Nanded, Maharashtra, India
}

\begin{abstract}
:
Background: Domestic violence against women is a global problem present in every country which adversely affects health of women. Research needs to be carried out to reveal the true situation in the society.

Objectives: 1. to find prevalence of domestic violence against married women in reproductive age group, 2. to ascertain its socio-demographic correlates, 3. to study its association with morbidities in women.

Material and methods: A community based cross sectional study was undertaken by interviewing 280 married women in reproductive age group residing in field practice area of Urban Health Training Centre during June 2009 to May 2010 with the help of predesigned and pretested questionnaire. The collected data was analyzed by using the software Epi Info version 6.

Results: Life time prevalence of domestic violence against married women was found to be 50.9\%. Prevalence of recent domestic violence which occurred during last 12 months was 47.9\%. On multiple logistic regression analysis, the significant correlates of the domestic violence were- husband's alcoholism, consanguinity of marriage, dowry demand and unemployment of respondents.

Slapping (96.4\%) and hitting with fist (55.4\%) were common physical and Insulting (90.4\%) and abusing (70.4\%) were common psychological modes of violence. Triggering factors for domestic violence weredissatisfaction regarding household work (45.9\%), disobeying family members (34.8\%), husband's alcoholism (31.1\%), economic hardship (14.8\%) and not taking care of in-laws (13.3\%), insufficient dowry (11.1\%), etc. $65.9 \%$ sufferers of domestic violence had one or other morbidities. Association of BMI and violence was also found to be significant. Out of 135 respondents who suffered from domestic violence, 79(58.5\%) had mild to severe depression.

Conclusion: This study emphasizes the need for justified women empowerment with multidisciplinary approach including health education and counseling which would most effectively address the problem of domestic violence.
\end{abstract}

Key words: Domestic violence, physical violence, psychological violence, reproductive age, morbidities

\section{Introduction}

Domestic violence against women means "any act of gender based violence that results in or is likely to result in physical, sexual or psychological harm or suffering to women including threats of such acts, coercion or arbitrary deprivation of liberty whether occurring in public or private life". ${ }^{1,2}$ Violence against woman occurs even before her life starts and continues throughout her whole life.

Domestic violence against women is a global problem and present in every country cutting across the boundaries of culture, class, education, income, ethnicity and age. ${ }^{3}$ Most of the population based studies in different countries indicate that $10-60 \%$ of ever-partnered or ever-married women have experienced at least one incidence of physical violence from a current or former intimate partner. ${ }^{4}$ Domestic violence against women particularly wife beating or physically coercive act is highly prevalent in India. National Family Health Survey 2005-06 in India (NFHS-3) reveals that the prevalence of violence against women in India is 37\% ranging from $6-59 \%$ in different states and that for Maharashtra (India) being $31 \%{ }^{5}$

In spite of approval of Protection of Women from Domestic Violence Bill 2005 by Government of India, large proportion of domestic violence goes unrevealed and unmeasured. Research needs to be carried out to reveal the true situation in the society. However, there is relative scarcity of population-based data. So, it has been decided to conduct the present study with the following objectives: 1. to determine the prevalence, characteristics and reasons of domestic violence against married women, 2. to ascertain the socio-demographic 
correlates of domestic violence against women, 3 . to study association of domestic violence against women with morbidities in them.

\section{MATERIAL AND METHODS}

Type of study: Community based cross sectional study.

Place of study: Field practice area of Urban Health Training Centre, Department of Preventive and Social Medicine, Dr. Shankarrao Chavan Government Medical College, Nanded, Maharashtra (India).

Duration of study: June 2010 to May 2011

Study population: Married women in age group 15-49 years living with their spouses and family members at least for past 12 months.

Sampling: The sample size for the study was calculated by assuming the prevalence of $31 \%$ and allowable error of $20 \%$. The calculated sample size was 214 . To reduce the error due to non-compliance, $25 \%$ additional sample was taken. Thus, the estimated sample size considered for this study was 280. Urban Health Training Centre of Government Medical College, Nanded caters its services for eight localities covering total population of 48,641. Of these, one locality i.e. Ambedkar Nagar was randomly selected by lottery method. As per the annual survey (2008-2009) carried out by the municipal corporation, Nanded, the population of this randomly selected locality was 4890 with 757 married women and 842 houses.

Data collection: After taking permission from the appropriate authorities, a house to house survey was conducted and informed verbal consent to participate in this study was obtained from all respondents and they were interviewed by authors themselves by maintaining the privacy and anonymity of the responses was guaranteed. If there were more than one married women in the house, one was selected randomly. Pre-designed, pre-tested structured questionnaire used for recording the responses included demographic information about the respondents and their husbands. Information was also obtained about type, frequency, modes of domestic violence and reasons for violence. Respondents were also examined clinically for presence of any morbidity in them. Depression in them was assessed by Beck's Depression Inventory-II (BDI-II) ${ }^{6}$ test.

Operational definition used in the study is: Violence against a woman by her husband or in-laws (father-inlaw, mother-in-law, sister-in-law or brother-in-law) in the form of - a) Physical violence (slapping, hitting with fist, beating, kicking, use or threat to use a weapon, throwing things on her, pulling hair, head banging, dragging, scorching). b) Psychological violence (insulting, abusing, threatening, abandoning, blame for theft).

Ethical approval: Methodology and procedure was reviewed and approved by Institutional Ethical Committee. Statistical analysis: The collected data was tabulated on Microsoft excel sheet and analyzed using the software Epi Info version 6.

\section{Results}

Out of 280 participants included in the study, 15(5.4\%) were excluded from the analysis as they did not give detailed information as per the proforma. Thus data obtained from 265 respondents was analyzed.

Out of 265 respondents, almost half i.e. 135(50.9\%) had experienced domestic violence at least once in their married life. 83(31.4\%) respondents suffered from physical violence and 135(50.9\%) respondents suffered from psychological violence at least once in their married life. Lifetime prevalence of psychological violence was similar to lifetime prevalence of all forms of violence. Prevalence of recent domestic violence against women which occurred during last 12 months was $47.9 \%$. 68(25.7\%) respondents suffered from physical violence and $127(47.9 \%)$ respondents suffered from psychological violence in last 12 months.

Prevalence of domestic violence among respondents in following characteristics was found to be significant- educated up to $10^{\text {th }}$ standard, respondents whose husbands were illiterate, unemployed respondents, respondents living in nuclear family, respondents who had given dowry for their marriage, consanguineous marriage, respondents having more than two children or having no male child, belonging to social class III and below and respondents whose husbands were alcoholic (Table 1)

Table 1: Relation of socio-demographic characteristics with domestic violence

\begin{tabular}{|c|c|c|c|}
\hline \multirow[t]{2}{*}{ Characteristics } & \multicolumn{2}{|c|}{ No. of respondents } & \multirow[t]{2}{*}{ OR (95\% CI) } \\
\hline & Total $(n=265)$ & Sufferers $(n=135)$ & \\
\hline \multicolumn{4}{|c|}{ Age group (in years) } \\
\hline $15-19$ & 11 & $04(36.4 \%)$ & \multirow[t]{5}{*}{$0.85(0.49-1.49)$} \\
\hline $25-29$ & 88 & $48(54.5 \%)$ & \\
\hline $30-34$ & 39 & $23(59 \%)$ & \\
\hline $35-39$ & 26 & $14(53.8 \%)$ & \\
\hline $45-49$ & 01 & $01(100 \%)$ & \\
\hline \multicolumn{4}{|c|}{ Education of respondents } \\
\hline Illiterate & 52 & $27(51.9 \%)$ & $2.21(1.12-4.38)$ \\
\hline
\end{tabular}


Domestic violence against married women in reproductive age group: A community based study.

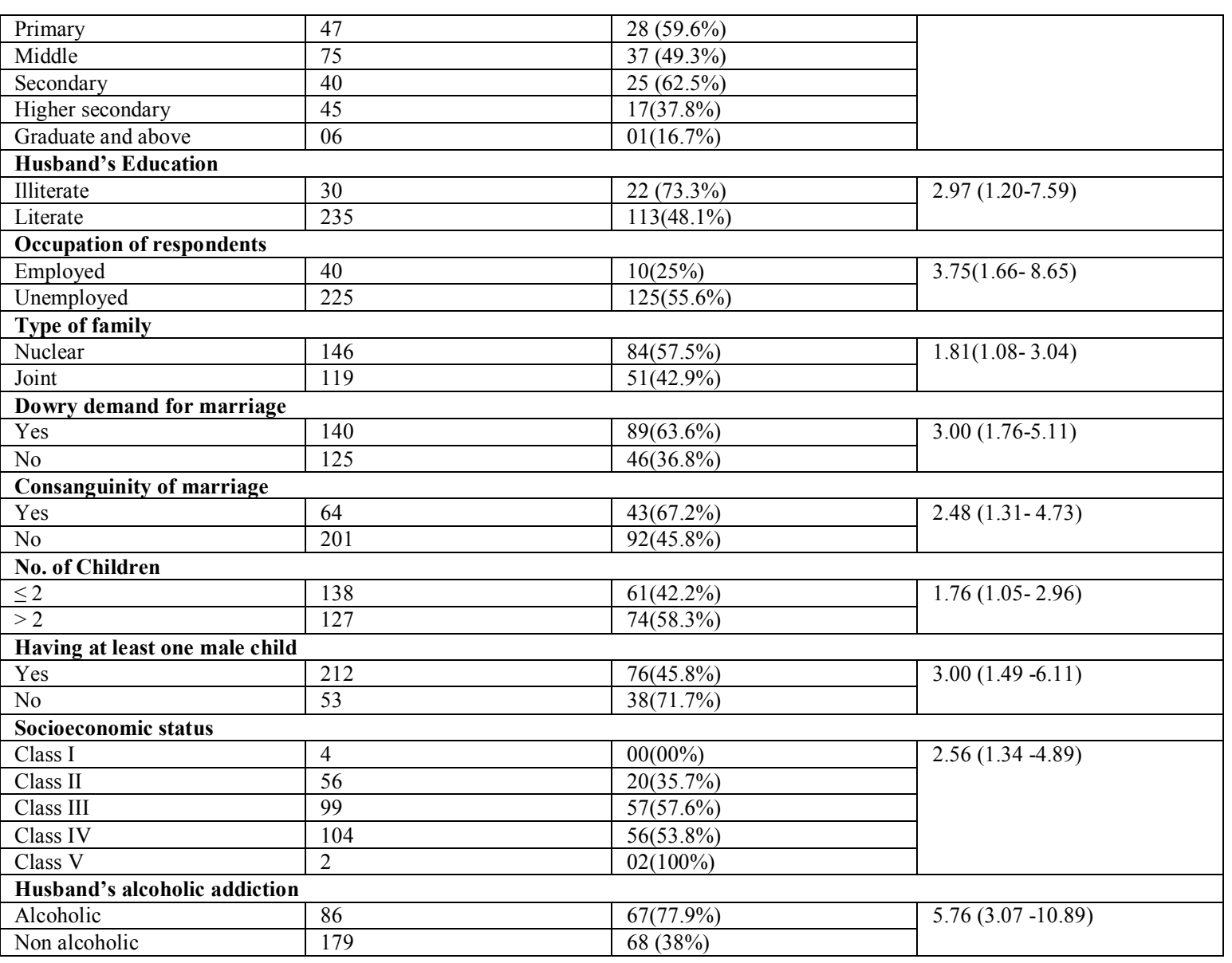

Frequency of recent violence was measured for both physical and psychological violence. Out of 68 respondents, 9(13.2\%) respondents said that physical violence occurred daily. $10(14.7 \%)$ and $27(39.7 \%)$ respondents said that it occurred twice a week and once a week respectively during past 12 months. Psychological violence was more common than physical violence. Out of 127 respondents, 54(42.5\%) respondents said it occurred daily while $11(8.7 \%)$ and 56(44.1\%) said that it occurred twice a week and once a week respectively.Slapping was the most common mode of physical violence i.e. in respondents $80(96.4 \%)$. Other common modes were hitting with fist $46(55.4 \%)$, beating with stick $25(30.1 \%)$, kicking $14(16.9 \%)$ and use or threat to use a weapon $7(8.4 \%)$, throwing objects $4(4.8 \%)$, pulling hair $4(4.8 \%)$, head banging $3(3.6 \%)$, dragging $1(1.2 \%)$ and scorching $1(1.2 \%)$. Insulting was the most common mode of psychological violence as reported by $122(90.4 \%)$ respondents followed by abusing $95(70.4 \%)$, abandoning $14(10.4 \%)$, threatening $9(6.7 \%)$ and blaming for theft $1(0.7 \%)$. Husband was the most common perpetrator involved in domestic violence as told by $107(79.3 \%)$ respondents followed by In-laws as told by $68(50.4 \%)$ respondents.

The various reasons cited by respondents as triggering factors for domestic violence were dissatisfaction of family members regarding household work 62(45.9\%), disobeying husband and family members $47(34.8 \%)$, husband's alcoholism $42(31.1 \%)$, economic hardship of family $20(14.8 \%)$ and not taking care of in-laws $18(13.3 \%)$, insufficient dowry $15(11.1 \%)$, going to parents' house $12(8.9 \%)$, having only female children $11(8.1 \%)$, having no children $9(6.7 \%)$, refusal for sex $8(5.9 \%)$, husband's illicit relationship $7(5.2 \%)$ and doubts about her character $3(2.2 \%)$.

On multiple logistic regression analysis, the significant correlates of the domestic violence were alcohol addiction in husband $(\mathrm{OR}=5.7,95 \% \mathrm{CI}=2.8-11.7)$, consanguinity of marriage $(\mathrm{OR}=3.3,95 \% \mathrm{CI}=1.6-$ 6.7), dowry demand $(\mathrm{OR}=3.6,95 \% \mathrm{CI}=2.0-6.5)$, and unemployment of respondents $(\mathrm{OR}=4.2,95 \% \mathrm{CI}=1.7-10.5)$ (Table 2).

Table 2: Correlates of domestic violence: Multiple Logistic Regression

\begin{tabular}{|l|l|l|l|}
\hline Variable & Adjusted Odds ratio & $95 \%$ Confidence Interval & P value \\
\hline Age of respondent & 1.1165 & $0.9539-1.3068$ & 0.1701 \\
\hline Alcohol addiction in husband & $\underline{5.7537}$ & $\underline{2.8288-11.6959}$ & $\underline{0.0000}$ \\
\hline Number of children & 1.1279 & $0.8295-1.5335$ & 0.4427 \\
\hline
\end{tabular}


Domestic violence against married women in reproductive age group: A community based study.

\begin{tabular}{|l|l|l|l|}
\hline Consanguinity of marriage & $\underline{3.2563}$ & $\underline{1.5921-6.6578}$ & $\underline{0.0012}$ \\
\hline Dowry demand & $\underline{3.5549}$ & $\underline{1.9519-6.4725}$ & $\underline{0.0000}$ \\
\hline Duration of marriage & 1.1457 & $0.9723-1.3501$ & 0.1044 \\
\hline Education of respondent & 1.6442 & $0.7169-3.7707$ & 0.2403 \\
\hline Family type & 1.6628 & $0.9107-3.0778$ & 0.0978 \\
\hline Education of husband & 2.0280 & $0.7006-5.8685$ & 0.1923 \\
\hline Unemployment & $\underline{4.2229}$ & $\underline{1.6920-10.5374}$ & $\underline{0.0020}$ \\
\hline Religion & 1.0696 & $0.7197-1.5898$ & 0.7392 \\
\hline Socio-economic status & 1.8775 & $0.9144-3.8552$ & 0.0861 \\
\hline
\end{tabular}

The leading morbidities among sufferers of domestic violence were - nutritional anemia 127(94.1\%), generalized body ache $45(33.3 \%)$, headache $11(8.1 \%)$, giddiness $8(5.9 \%)$, dyspareunia $8(5.9 \%)$, irregular menses $7(5.2 \%)$, lower abdominal pain 6(4.4\%), dysmenorrhea 6(4.4\%), dyspepsia 6(4.4\%), infertility 5(3.7\%).

Out of 135 respondents who suffered from domestic violence, $89(65.9 \%)$ had one or other morbidity while out of 130 non-sufferers 60(46.2\%) had morbidities (Table 3).

Table 3: Morbidities among respondents and domestic violence

\begin{tabular}{|l|l|l|l|}
\hline \multirow{2}{*}{ Morbidities } & \multicolumn{2}{|c|}{ Respondents } & \multirow{2}{*}{ Total (\%) } \\
\cline { 2 - 3 } & $\begin{array}{l}\text { Suffered from } \\
\text { Violence (\%) }\end{array}$ & $\begin{array}{l}\text { Not suffered from violence } \\
(\%)\end{array}$ & $149(56.2)$ \\
\hline Present & $89(65.9)$ & $60(46.2)$ & $116(43.8)$ \\
\hline Absent & $46(34.1)$ & $70(53.8)$ & $265(100.0)$ \\
\hline Total & $135(100.0)$ & $130(100.0)$ & \\
\hline
\end{tabular}

$$
\left(\mathrm{OR}=2.26, \mathrm{CI}=1.33-3.82 ; \mathrm{X}^{2}=10.52, \mathrm{df}=1, \mathrm{P}<0.01\right)
$$

This difference in presence of morbidities in sufferers and non-sufferers of domestic violence was statistically highly significant $\left(\chi^{2}=10.52, \mathrm{df}=1, \mathrm{P}=0.001 ; \mathrm{OR}=2.26, \mathrm{CI}=1.33-3.82\right)$.

Effect of domestic violence on nutritional status of the respondents was assessed with the help of body mass index (BMI). Of 135 respondents suffering from domestic violence, 63(46.7\%) were underweight (BMI less than $18.5 \mathrm{~kg} / \mathrm{m}^{2}$ ) while out of 130 non-sufferers $29(22.3 \%)$ were underweight (Table 4$)$. This difference was statistically highly significant. $\left(\chi^{2}=17.34, \mathrm{df}=1, \mathrm{P}<0.001 ; \mathrm{OR}=3.05, \mathrm{CI}=1.73-5.39\right)$.

Table 4: Body mass index and domestic violence among respondents

\begin{tabular}{|l|l|l|l|}
\hline Classification of BMI $\left(\mathrm{kg} / \mathrm{m}^{2}\right)$ & $\begin{array}{l}\text { Suffered from } \\
\text { violence (\%) }\end{array}$ & $\begin{array}{l}\text { Not suffered from violence } \\
(\%)\end{array}$ & Total (\%) \\
\hline Underweight $(<18.50)$ & $63(46.7)$ & $29(22.3)$ & $92(34.7)$ \\
\hline Normal $(\geq 18.50)$ & $72(53.3)$ & $101(77.7)$ & $173(65.3)$ \\
\hline Total & $135(100.0)$ & $130(100.0)$ & $265(100)$ \\
\hline
\end{tabular}

$\left(\mathrm{OR}=3.05, \mathrm{CI}=1.73-5.39 ; \mathrm{X}^{2}=17.34, \mathrm{df}=1, \mathrm{P}<0.001\right)$

In the present study, of 83 respondents suffering from physical violence, 57(68.7\%) were having injury at the time of survey. Of these, 26(45.6\%) sought healthcare. Various reasons for not seeking healthcare were husband didn't allow $8(25.8 \%)$, fear of more violence 7(22.6\%), social restriction $6(19.4 \%)$, lack of money $5(16.1 \%)$, in-laws didn't allow 3(9.7\%), women felt it's not important 2(6.5\%).

Table 5: Classification of depression as per BDI II among respondents and domestic violence

\begin{tabular}{|l|c|l|c|}
\hline Depression & Suffered from violence & $\begin{array}{l}\text { Not suffered from } \\
\text { violence }\end{array}$ & Total (\%) \\
\hline Minimal & $56(41.5)$ & $95(73.1)$ & $151(56.9)$ \\
\hline Mild & $49(36.3)$ & $22(16.9)$ & $71(26.8)$ \\
\hline Moderate & $25(18.5)$ & $13(10.0)$ & $38(14.4)$ \\
\hline Severe & $05(03.7)$ & $00(00.0)$ & $05(01.9)$ \\
\hline Total & $135(100)$ & $130(100)$ & $265(100)$ \\
\hline
\end{tabular}

$\left(\mathrm{OR}=3.83, \mathrm{CI}=2.21-6.65 ; \mathrm{X}^{2}=26.97, \mathrm{df}=1, \mathrm{P}<0.001\right)$

Table 5 shows classification of depression as per BDI-II ${ }^{7}$ among respondents. Out of 135 respondents who suffered from domestic violence, $79(58.5 \%)$ had mild to severe depression while out of 130 non-sufferers 
only $35(26.9 \%)$ had mild to severe depression. This difference was found to be statistically highly significant. $\left(\chi^{2}=26.97\right.$, d.f. $\left.=1, \mathrm{P}<0.001 ; \mathrm{OR}=3.83, \mathrm{CI}=2.21-6.65\right)$

\section{Discussion}

In the present study, lifetime prevalence of domestic violence against women was found to be $50.9 \%$ for all forms of violence ( $95 \%$ CI: $44.9 \%$ to $57.1 \%$ ). The studies conducted by Jain et $\mathrm{al}^{7}$ in Maharashtra and Dogan et $\mathrm{al}^{8}$ in Turkey also mentioned high prevalence of domestic violence i.e. $48 \%$ and $52 \%$ respectively.

In the present study, prevalence of domestic violence in older women ( 40 to 44 years) was found to be less i.e. $37.5 \%$. It is supposed that older women have better crisis management skills than younger women and therefore they are likely to experience less domestic violence. Again prevalence is less in very young married women (15 to 19 years) i.e. $36.4 \%$. This may be due to short duration of marital life they spent. The ICRW $(2000)^{9}$ survey in India also revealed that chances of domestic violence were less for older women when compared to younger women.

In present study, the socio-demographic characteristics significantly associated with the domestic violence against women were - having lower educational status of respondents, unemployment of respondents, illiterate husbands, living in nuclear family, having lower socio-economic status.

Association of domestic violence against married women and lower education, unemployment and lower socio-economic status was seen in various other studies ${ }^{5,9}$, 10. Employment, education, improved socioeconomic condition etc. are the factors which contribute to empowerment of women in society. Such women are self dependent and are in better position to cope up with the incidences of violence which occur in the house. Further, an employment improves socio-economic status of family and consequently reduces domestic violence. In communities where women are deprived of from employment, education, improved socioeconomic conditions, the prevalence of domestic violence against women is found to be more.

Again it is observed that domestic violence against women is associated with illiteracy or lower education of husband as seen in the study by Panda $\mathrm{P}^{11}$. Because of illiteracy the husbands find it difficult to get the job and thus have poor socio-economic condition. In such condition they find it difficult to manage the household chores easily which sometimes results in violence against women.

In present study respondents living in nuclear family were more exposed to violence than those living in joint family. Study by CWSD ${ }^{10}$ and NFHS-3 ${ }^{5}$ survey showed similar findings. In nuclear families there is no one to interrupt the process of violence between perpetrator and victim. Prevalence of domestic violence was very high i.e. $77.9 \%$ in respondents whose husbands were alcoholic. Similar findings were observed in studies ${ }^{6,10,12}$. The dis-inhibition associated with alcohol may result in low threshold to violence. Alcohol use and household neglect resulting from it facilitate development of marital disharmony, relationship tension resulting in violence. ${ }^{13}$

Prevalence of domestic violence was found to be more in respondents having no male child. Having no male child in the house led to perpetration of domestic violence as still there are beliefs such as male child is must for propagation of future generation and for economic purpose and support in old age. It is also more in those having large family size as seen in the present study that domestic violence was significantly more in respondents with more than two children. This might be because of increase in family size and less per capita income leading to lower socio-economic status and consequently more domestic violence.

Also it was found in the present study that the respondents who had undergone consanguineous marriage had suffered more from domestic violence. There is no obvious reason for high prevalence of domestic violence against women in consanguineous marriages but further analysis revealed that in this study, in majority i.e. in $62.5 \%$ of consanguineous marriages, dowry was demanded which might be the main reason of domestic violence in these type of marriages. Domestic violence is used in India to extract dowry payments and other property from the families of young married women. Violence - often of escalating severity over time - may be perpetrated against women in conjunction with demands for outstanding (often unaffordable) dowry payments or demands for additional amounts. ${ }^{14}$

When data was analyzed with Multiple Logistic Regression, it was found that alcohol addiction in husband, consanguinity of marriage, dowry demand for marriage and unemployment of respondents were associated with domestic violence against women.

Most common modes of physical violence in the present study were slapping $(96.4 \%)$, hitting with fist (55.4\%), beating with stick (30.1\%), and kicking (16.9\%). Many of these modes of physical violence are somewhat similar across various studies. ${ }^{15,16,17}$ Most common modes of psychological violence were insulting (90.4\%) and abusing (70.4\%). Husband and mother-in-law were the most common perpetrators involved in domestic violence. Similar results were also observed in studies by Panda $\mathrm{P}^{11}$ and INCLEN . 
Most common reasons cited by respondents as triggering factors for domestic violence were dissatisfaction for family members regarding household work (45.9\%), disobeying husband and family members (34.8\%) and husband's alcohol addiction (31.1\%). Similar reasons were also cited in various studies ${ }^{9,11}$.

Morbidities were significantly more common in respondents who had suffered from domestic violence (59.7\%) than in those who did not suffer from it (40.3\%). Out of 83 respondents who had suffered from physical violence, $68.7 \%$ had injury. Only half of these sought healthcare. Similar results were found in several other studies. ${ }^{8,9,11,15}$

The association between domestic violence and being underweight was found to be statistically significant. Ackerson L K et al ${ }^{18}$ reported in their study that women who reported more than one instance of domestic violence in the previous year had an increased likelihood of being underweight or having anemia. Choudhary $\mathrm{N}$ et $\mathrm{al}^{19}$ in their study in Goa observed that domestic violence was found to increase risk of low BMI.

Women suffering from domestic violence neglect their health and nutrition by consumption of less food, avoiding healthcare seeking for health problems. This leads to chronic under nutrition reflecting as anemia and low body mass index. Association between exposure to domestic violence and malnutrition among women can be explained as follows - perpetrators of domestic violence often use several types of abuse i.e. physical or psychological to control behaviour of their family members. ${ }^{20}$ The withholding of food is a documented form of abuse in Indian households and is likely correlated with the perpetration of physical violence. ${ }^{21}$ An inadequate diet resulting from this withholding of food through psychological or emotional abuse could mediate the relation between physical domestic violence and nutrient deficiencies that cause anaemia and underweight. Additionally, domestic violence is strongly associated with a woman's inability to make decisions for herself and her family including the choice of types and quantities of food that a woman prepares as she cares for herself. ${ }^{22}$

In this study, effect of domestic violence on mental health was assessed by BDI-II ${ }^{6}$. A statistical significant association was observed between depression and domestic violence amongst respondents. Similar findings were also observed by Kumar $\mathrm{S}$ et al ${ }^{23}$ and Vachhar $\mathrm{A}$ et al ${ }^{24}$. Women with violence were more likely to have unhealthy mental status than without violence. Hence any married woman in reproductive age group having depression should be screened for domestic violence.

\section{Conclusions}

This study emphasizes the need for justified women empowerment with multidisciplinary approach like improving the educational status, economic productivity of women etc. which may help reduce this social as well as public health evil. To mitigate problem of domestic violence against women need sustained educational campaign to bring change in the community's attitude particularly those of female themselves. Health care personnel should also play their role to reduce the severity of domestic violence against women by managing cases of domestic violence promptly and appropriately.

\section{References}

[1]. Heise L., Ellsberg M. and Gottemoeller M. (1999) Ending Violence against Women. Population Reports, Series L, No 11. Baltimore: Johns Hopkins University School of Public Health.

[2]. United Nations Children's Fund (UNICEF). Domestic violence against women and girls. United Nations Children's Fund. Innocenti Digest, no. 6. Florence: UNICEF Innocenti Research Centre; June 2000.

[3]. Burge SK. Partner violence. In: Rosenfeld JA, Acheson LS, Admire JB eds. Women's health in primary care. Pennsylvania, USA, Williams \& Wilkins, 1997: 241-255

[4]. Krug E G, Dahlberg L L, Mercy J A, Anthony B Z, Lozano R; World report on violence and health; World Health Organization Geneva 2002

[5]. NFHS-III (2007): Report of National Family Health Survey NFHS-III (2005-06), Ministry of Health and Family Welfare, Government of India.

[6]. Beck AT, Steer RA, Ball R, Ranieri W (December 1996). "Comparison of Beck Depression Inventories -IA and -II in psychiatric outpatients". Journal of personality assessment 67 (3): 588-97

[7]. Jain D, Sanon S, Sadowski, Hunter W. Violence against women in India: evidence from rural Maharashtra, India. Rural and Remote Health 4(online), 2004: no. 304

[8]. Dogan O, Kocacik F. Domestic Violence against Women in Sivas, Turkey: Survey Study. Croat Medical Journal, 2006; 47: 742-9

[9]. International Clinical Epidemiologists Network (INCLEN) Domestic violence in India; A summary report of a Multi-site household survey. International Centre for Research on Women; Washington, DC; May 2000

[10]. Centre For Women's Studies \& Development, The Research Institute, Rajagiri College of Social Sciences, Rajagiri P.O, Kalamassery, Kochi, Kerala. A Situational Analysis of Domestic Violence Against Women In Kerala. September 2005.

[11]. Panda P. Domestic violence against women in Kerala. Kerala Research Programme on Local Level Development, Centre for Development Studies, Thiruvananthapuram. Discussion Paper no. 86

[12]. Choudhary A, Giridhar S., Soni R. K.. Epidemiological Correlates of Domestic Violence in Married Women in Urban Area of Ludhiana, Punjab, India. The Internet Journal of Health, 2009 volume 9 Number 1

[13]. Ntaganira J, Muula A S, Masaisa F, Dusabeyezu F, Siziya S, Rudatsikira. Intimate partner violence among pregnant women in Rwanda. BMC Women's Health 2008, 8:17

[14]. Bates LM, Schuler SR, Islam F, Islam MK. Socio-economic factors and processes associated with domestic violence in Rural Bangladesh. International Family Planning Perspectives, 2004, 30(4):190-199. 
[15]. Bhuiya A, Sharmin T, Hanifi S M A. Nature of Domestic Violence against Women in a Rural Area of Bangladesh: Implication for Preventive Interventions. J Health Popul Nutr 2003 Mar; 21(1):48-54

[16]. Bruschi, Alessandra; Paula, Cristiane Silvestre De And Bordin, Isabel Altenfelder Santos. Lifetime Prevalence And Help Seeking Behavior In Physical Marital Violence. Rev. Saúde Pública [Online]. 2006, Vol.40, N.2, Pp. 256-264. Issn 0034-8910

[17]. Ruikar M, Pratinidhi A. Physical wife abuse in an urban slum of Pune, Maharashtra. Indian Journal of Public Health,2008; vol.52,no.4, page 215-7

[18]. Ackerson L K, Subramanian S V. Domestic violence and chronic malnutrition among women and children in India. American Journal of Epidemiology, 2008 May 15; 167(10): 1188-1196.

[19]. Chowdhary N, Patel V. The effect of spousal violence on women's health: Findings from the Stree Arogya Shodh in Goa, India. J Postgrad Med 2008; 54: 306-12

[20]. Pence E, McDonell C. Power and control wheel. Duluth M N: Domestic abuse intervention project.

[21]. Raj A, Livramento K N, Santana M C, et al. Victims of intimate partner violencemore likely to report abuse from in-laws. Violence Against Women 2006;12:936-49.

[22]. Sethuraman K, Lasdown R, Sullivan K. Women's empowerment and domestic violence: the role of socio-cultural determinants in maternal and child under nutrition in tribal and rural communities in South India. Food Nutr Bull 2006;27:128-43

[23]. Kumar S, Jeyaseelan L, Suresh S, Ahuja R. Domestic violence and its mental health correlates in Indian women. British Journal of Psychiatry (2005), 187, 62-67

[24]. Vachher A S, Sharma A K. Domestic violence against women and their mental health status in a colony in Delhi. Indian J Community Med 2010;35:403-5 